\section{Verification of Thermodynamic Models for Predict- ing Grain Boundary Segregation of Carbon and Nitrogen in Ferritic Steels}

\author{
Yuxiong ZHOU, ${ }^{1) *}$ Takuro MASUMURA ${ }^{2,3)}$ and \\ Toshihiro TSUCHIYAMA ${ }^{2,3,4)}$
}

1) Graduate School of Engineering, Kyushu University, 744, Moto-oka, Nishi-ku, Fukuoka, 819-0395 Japan.

2) Department of Materials Science and Engineering, Graduate School of Engineering, Kyushu University, 744, Moto-oka, Nishiku, Fukuoka, 819-0395 Japan.

3) International Institute for Carbon-Neutral Energy Research (WPI-I2CNER), Kyushu University, 744, Moto-oka, Nishi-ku, Fukuoka, 819-0395 Japan.

4) Research Center for Steel, 744, Moto-oka, Nishi-ku, Fukuoka, 819-0395 Japan.

(Received on August 16, 2021; accepted on September 24, 2021)

The concentrations of $\mathrm{C}$ and $\mathrm{N}$ segregated at the grain boundaries $(\mathrm{GB})$ in $\mathrm{Fe}-\mathrm{C}, \mathrm{Fe}-\mathrm{N}$ binary alloys, and $\mathrm{Fe}-\mathrm{C}-\mathrm{N}$ ternary alloys were calculated using the McLean and the Hillert-Ohtani models. Comparison of the calculated data with experimental values obtained by three-dimensional atom probe tomography (3DAP) revealed that the experimental values were roughly explained by the Hillert-Ohtani model for the binary alloys. The McLean model also can predict similar results when the fraction of available sites in the GB layer is assumed to be saturated at 0.1. On the other hand, the Hall-Petch coefficient $\left(k_{y}\right)$ of $\mathrm{Fe}-\mathrm{C}-\mathrm{N}$, determined from tensile tests, was linearly related to the predicted concentrations of segregated $\mathrm{C}$ and N. Proposedly, $k_{y}$ can be predicted from the chemical composition and heat treatment temperature via thermodynamic calculations.

KEY WORDS: segregation; grain boundary; interstitial element; Hall-Petch coefficient; thermodynamics.

\section{Introduction}

The yield strength of polycrystalline metals increases linearly as a function of the inverse of the square root of the grain size. This relationship is referred to as the HallPetch relationship. ${ }^{1)}$ For the grain refinement strengthening, authors demonstrated that the yield strength of ferritic steels is significantly enhanced by segregation of the $\mathrm{C}$ and $\mathrm{N}$ atoms at the grain boundary (GB), reflected by an increase in the slope of the Hall-Petch plot (Hall-Petch coefficient; $\left.k_{y}\right)^{2}{ }^{2}$ Therefore, the grain refinement strengthening in ferritic steels should be discussed in terms of not only the grain size but also the concentrations of $\mathrm{C}$ and $\mathrm{N}$ segregated at the GB.

Since the experimental determination of the concentrations of segregated $\mathrm{C}$ and $\mathrm{N}$ is not generally easy, theoreti-

\footnotetext{
* Corresponding author: E-mail: zhou.yuxiong.408@s.kyushu-u.ac.jp
}

cal thermodynamic models have been applied to predict the equilibrium segregation concentration of these solute atoms. The McLean model is the most frequently used method for estimating the solute concentration at the $\mathrm{GB},{ }^{3,4)}$ as shown in Eq. (1).

$$
\frac{X_{g b}}{X_{g b}^{*}-X_{g b}}=\frac{X_{0}}{1-X_{0}} \exp \left(\frac{G}{R T}\right) \text {............. }
$$

where $X_{g b}, X_{g b}^{*}, X_{0}, G$, and $R$ are the concentrations of solute atoms at the GB, the fraction of available sites to all segregation sites in the GB layer, bulk concentration of solute atoms, free energy of segregation, and gas constant, respectively. The value $X_{g b}^{*}$ is often assumed to be 1 , and Eq. (1) can thus be expressed as Eq. (2), as follows:

$$
\frac{X_{g b}}{1-X_{g b}}=\frac{X_{0}}{1-X_{0}} \exp \left(\frac{G}{R T}\right)
$$

The concentration of the atoms segregated at the GB can be evaluated by using this equation when the free energy of segregation, $G$, is known. However, it is still difficult to determine the exact values of $G$ because of the variety of the reported values depending on the measurement conditions. Additionally, the fraction of available sites to all segregation sites in the GB layer, $X_{g b}^{*}$, remains unclear. If we assume $X_{g b}^{*}$ is 1 in an interstitially alloyed iron so that Eq. (2) holds, then it might mean that all the octahedral sites are saturated with segregated atoms in a bcc lattice. However, considering the interaction of these adjacent atoms, such a saturated state is unlikely to be realized.

Recently, another model was proposed for estimating the concentration of segregated atoms at GB using the thermodynamic theory proposed by Hillert et al. ${ }^{5)}$ The model to be discussed simply states that the GB has a constant thickness, where the atoms in the GB can be regarded as belonging to a separate phase. For this alloy, we consider the equilibrium between the GB phase and the matrix phase. Under the condition that the number of atoms in the GB is constant, the following equation is introduced:

$$
\frac{d G^{g b}}{d X^{g b}}=\frac{d G^{\text {matr }}}{d X^{\text {matr }}}
$$

Here, $G^{g b}$ and $G^{\text {matr }}$ are the Gibbs free energies of the GB and the matrix phases, respectively; $X^{g b}$ and $X^{\text {matr }}$ are the atomic fraction of the solute in the GB and the matrix phases, respectively. To determine the concentration of atoms segregated at GB, $X^{g b}$, the free energies of GB and matrix phases, $G^{\text {matr }}$ and $G^{g b}$, need to be determined. However, because the thermodynamic information of the GB is insufficiently known, it is difficult to obtain the available values of $G^{g b}$. To deal with this problem, Ohtani assumed that the $G^{g b}$ would be thermodynamically equivalent to the Gibbs free energy of the liquid phase, $G^{\text {liq }}{ }^{6)}$ In fact, a similarity in structure between GB and amorphous state was demonstrated by using molecular dynamics simulation. Under this assumption, Eq. (3) can be rewritten as Eq. (4) as follows.

$$
\frac{d G^{\text {liq }}}{d X^{g b}}=\frac{d G^{\text {matr }}}{d X^{\text {matr }}}
$$

The equilibrium solute concentrations in both matrix and GB phase can be evaluated from the contact values by drawing the parallel tangent (or parallel contact surface) of the free energy curves (or curved surfaces) obtained by Thermocalc. In addition, Hillert-Ohtani model with Thermo-calc can be applied to not only binary system but also ternary or quaternary systems, where each interaction of all contained elements is taken into account. 


\section{Experimental Procedure}

In order to estimate the concentrations of segregated $\mathrm{C}$ and $\mathrm{N}$ by these theoretical thermodynamic models mentioned above, it is necessary to verify which model is better for the evaluation of grain boundary segregation and the subsequent discussion on grain refinement strengthening enhanced by $\mathrm{C}$ and $\mathrm{N}$. In this study, the $\mathrm{C}$ and $\mathrm{N}$ segregation behavior in ferritic steel at $973 \mathrm{~K}$ was treated with the McLean and the Hillert-Ohtani models, and the equilibrium concentrations of $\mathrm{C}$ and $\mathrm{N}$ at GB were respectively calculated. Then they were compared with the experimental values obtained by 3DAP that the authors reported previously ${ }^{7}$ ) to assess the accuracy of these two models.

The calculations were applied to the steels used in Takeda's previous work. ${ }^{2)}$ The chemical compositions of the steels are listed in Table 1. Conventional pure iron specimens with different amounts of $\mathrm{C}$ and $\mathrm{N}$ were investigated. Interstitial-free (IF) steel was also used for comparison. All of the specimens were annealed in a ferrite single phase region at $973 \mathrm{~K}$, followed by water quenching. For the calculation of McLean model, the free energies of segregation for $\mathrm{C}$ and $\mathrm{N}$ were quoted from the Grabke's report as 78 $\mathrm{kJ} / \mathrm{mol}$ and $58 \mathrm{~kJ} / \mathrm{mol}$, respectively. ${ }^{8)}$ For the Hillert-Ohtani model, the calculation was performed under the following conditions: temperature $=973 \mathrm{~K}$, number of moles $=1$ mol, and atmospheric pressure $=101325 \mathrm{~Pa}$. The SSOL7 database was used in this study.

To determine the influence of $X_{g b}^{*}$ on the results of the McLean model, the calculations for the $\mathrm{Fe}-\mathrm{C}$ and $\mathrm{Fe}-\mathrm{N}$ binary alloys were performed with different values of $X_{g b}^{*}$. The real values of segregated $\mathrm{C}$ and $\mathrm{N}$ in $\mathrm{C} 60$ and for N60 annealed at $973 \mathrm{~K}$ were measured by means of threedimensional atom probe tomography (3DAP) (Table 1). $\left.{ }^{9}\right)$ However, since 3DAP only shows the number of solute atoms per unit area, the interfacial excess at the GB (atoms/1 $\mathrm{nm}^{2}$ ) cannot be directly compared with the calculated results expressed as the atomic fraction. Therefore, the interfacial excess must be converted to the concentration of atoms segregated at the GB expressed with atomic fraction. Then we attempted a rough estimation as follows. In the case of $\mathrm{Fe}-\mathrm{C}$ or $\mathrm{Fe}-\mathrm{N}$, a $1 \mathrm{~nm}^{2}$ area has approximately $16(4 \times 4)$ atoms of Fe (diameter: $0.25 \mathrm{~nm}$ ). In this study, the GB was considered as a two-atom-thick layer $(0.5 \mathrm{~nm}$ thick). Based on this situation, the GB layer had $32(16 \times 2)$ Fe atoms. In addition, assuming that the segregated $\mathrm{C}$ and $\mathrm{N}$ atom occupy the octahedral sites even in the GB layer, one Fe atom possesses three octahedral sites, and thus, there are $96(32 \times 3)$ interstitial sites per $1 \mathrm{~nm}^{2}$ of GB area. If all of the sites were available for segregation, the value of $X_{g b}^{*}$ could be regarded as 1 . The concentration of segregated $\mathrm{C}$ or $\mathrm{N}$ at the $\mathrm{GB}$ can be calculated by dividing the number of segregated atoms (interfacial excess) by the number of interstitial sites in the GB layer. The calculation was also performed for the $\mathrm{Fe}-$

Table 1. Chemical compositions of polycrystalline ferritic steels used for calculation in this study (mass ppm). ${ }^{2)}$

\begin{tabular}{ccccccccc}
\hline & $\mathrm{C}$ & $\mathrm{N}$ & $\mathrm{Si}$ & $\mathrm{Mn}$ & $\mathrm{P}$ & $\mathrm{S}$ & $\mathrm{Ti}$ & $\mathrm{Fe}$ \\
\hline Base & 5 & 9 & $<30$ & $<30$ & $<20$ & $<3$ & $<20$ & Bal. \\
C30 & 28 & 11 & $<30$ & $<30$ & $<20$ & $<3$ & - & Bal. \\
C60 & 56 & 11 & $<30$ & $<30$ & $<20$ & $<3$ & - & Bal. \\
N30 & 11 & 24 & $<30$ & 370 & $<20$ & $<3$ & - & Bal. \\
N60 & 5 & 54 & $<30$ & 830 & $<20$ & $<3$ & - & Bal. \\
C30N60 & 35 & 26 & $<30$ & 380 & $<20$ & $<3$ & - & Bal. \\
IF-steel & 4 & 10 & $<30$ & $<30$ & $<20$ & $<3$ & 240 & Bal. \\
\hline
\end{tabular}

C-N ternary alloy to consider the effect of the interaction between $\mathrm{C}$ and $\mathrm{N}$.

\section{Results and Discussion}

Figure 1 displays the estimated $\mathrm{C}$ and $\mathrm{N}$ concentrations segregated at the GB, obtained by the McLean model with different values of $X_{g b}^{*}$. When $X_{g b}^{*}=1$, the calculated result showed that approximately $90 \%$ of the GB was filled with C, which is a very unlikely situation. The amount of segregated $\mathrm{C}$ varied from approximately $90 \%$ to $10 \%$ when $X_{g b}^{*}$ was changed from 1 to 0.1 . The calculated data for $\mathrm{N}$ also tended to decrease with a reduction in $X_{g b}^{*}$, although the amount of segregated $\mathrm{N}$ was much smaller than that of $\mathrm{C}$. This observation indicates that a suitable $X_{g b}^{*}$ is important for obtaining an accurate prediction using the McLean model. In Fig. 2, the bold lines show the concentrations of segregated $\mathrm{C}$ and $\mathrm{N}$ that were calculated using the Hillert-Ohtani model. The results of Fig. 1 are also presented with the broken lines for comparison. In addition, the experimental results of 3DAP for $\mathrm{C} 60$ and $\mathrm{N} 60$ are plotted with quadrilateral marks. It was found that the results of the Hillert-Ohtani model were close to the experimental results for both the $\mathrm{Fe}-\mathrm{C}$ and $\mathrm{Fe}-\mathrm{N}$ alloys. Thus, it was inferred that the Hillert-Ohtani model was nearly reliable in predicting the concentration of atoms segregated at the GB. The McLean model was also consistent with the experimental results when $X_{g b}^{*}$ was approximately 0.1 , which means that the segregated $\mathrm{C}$ and

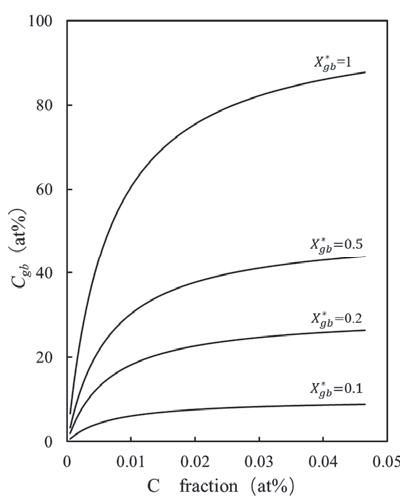

(a)

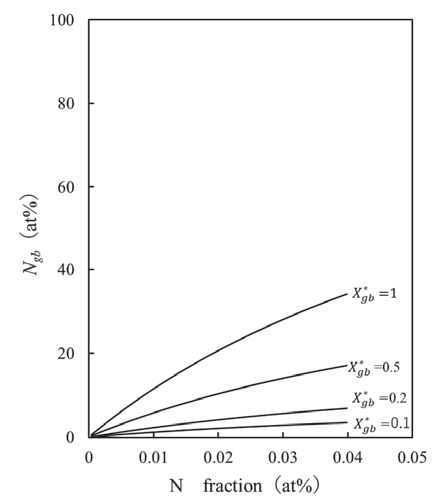

(b)
Fig. 1. Concentrations of $\mathrm{C}$ and $\mathrm{N}$ segregated at GB calculated with McLean model using different $X_{g b}^{*}$.

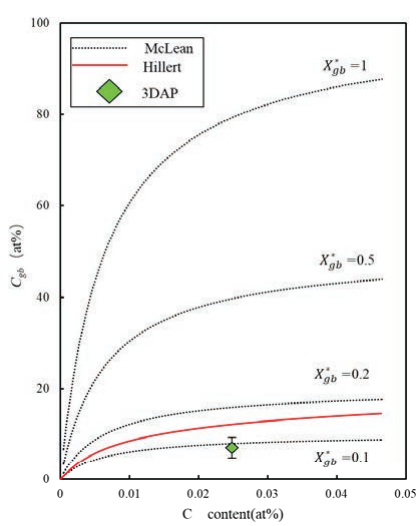

(a)

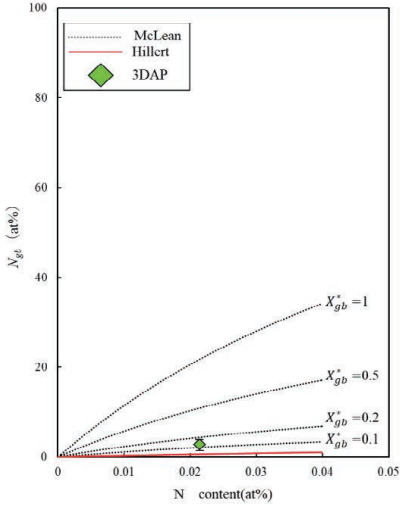

(b)
Fig. 2. Concentrations of $\mathrm{C}$ and $\mathrm{N}$ segregated at $\mathrm{GB}$ calculated with Hillert-Ohtani model and experimental values obtained by 3DAP. The broken lines are the results of Fig. 1. (Online version in color.) 
$\mathrm{N}$ would be saturated when approximately one-tenth of all the interstitial sites were filled in the GB.

In the case of $\mathrm{Fe}-\mathrm{C}-\mathrm{N}$ ternary alloys, there should be some interaction between the $\mathrm{C}$ and $\mathrm{N}$ atoms, which would change the segregation behavior of both elements. Figure 3(a) shows the changes in the concentration of segregated $\mathrm{C}$ as a function of the $\mathrm{C}$ content with the addition of $\mathrm{N}$ at $0,0.005$ at $\%$ and 0.01 at $\%$. Figure 3(b) shows the concentration of segregated $\mathrm{N}$ as a function of the $\mathrm{N}$ content with the addition of $\mathrm{C}$ at $0,0.005$ at $\%$ and 0.01 at $\%$. These calculations were performed using the Hillert-Ohtani model. Figure 3(a) demonstrates that there is little change in the concentration of segregated $\mathrm{C}$, even when $\mathrm{N}$ was coexistent in steel. On the other hand, Fig. 3(b) shows that the amount of segregated $\mathrm{N}$ declined drastically with an increase in the coexisting C. Only 0.005 at $\% \mathrm{C}$ caused a $70 \%$ decrease in the concentration of $\mathrm{N}$ segregated at the GB. The results suggest that the tendency of $\mathrm{C}$ atoms to segregate at the GB is much stronger than that of $\mathrm{N}$, and thus, the segregation behavior of $\mathrm{C}$ was less affected by $\mathrm{N}$ atoms. In contrast, $\mathrm{N}$ segregation was significantly hindered by $\mathrm{C}$.

Now back to the discussion on the relationship between Hall-Petch coefficient $\left(k_{y}\right)$ and the segregated $\mathrm{C}$ and $\mathrm{N}$ concentrations. First, the concentration of segregated atoms was calculated with the Hillert-Ohtani model for seven $\mathrm{Fe}-\mathrm{C}-\mathrm{N}$ alloys, including IF steel used by Takeda, ${ }^{2}$ and then the

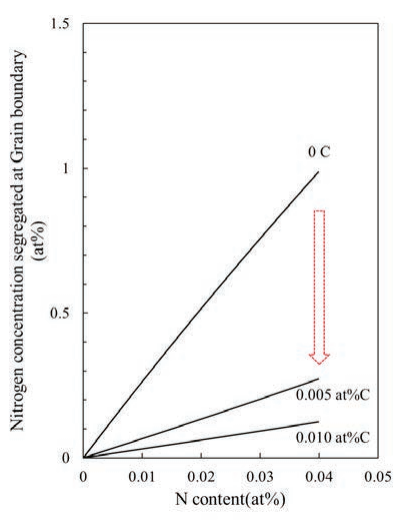

(a)

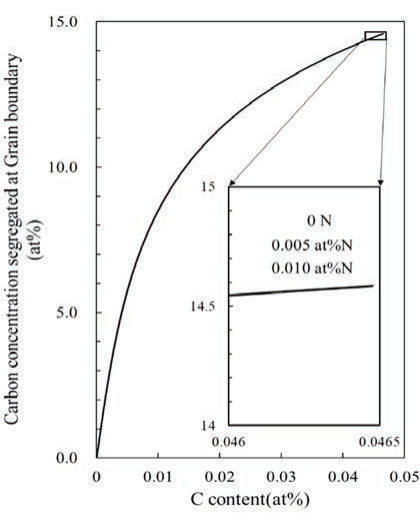

(b)
Fig. 3. $\mathrm{C}$ and $\mathrm{N}$ concentrations segregated at $\mathrm{GB}$ in $\mathrm{Fe}-\mathrm{C}-\mathrm{N}$ ternary alloys showing the interaction between $\mathrm{C}$ and $\mathrm{N}$, calculated by Hillert-Ohtani model. (Online version in color.)

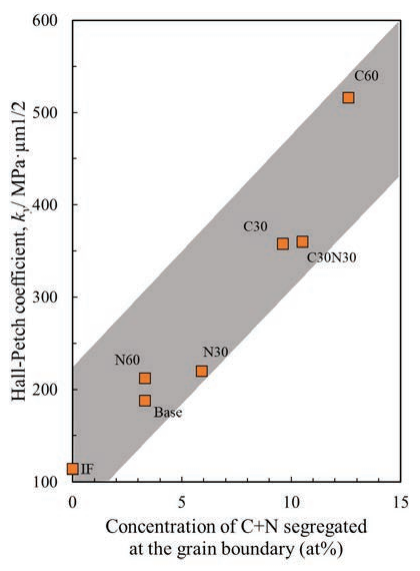

(a)

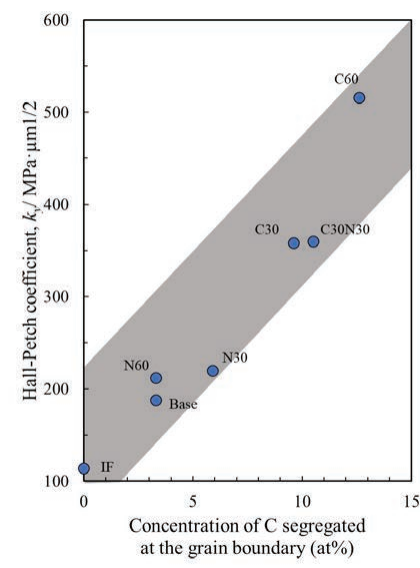

(b)
Fig. 4. Relationship between Hall-Petch coefficient and $\mathrm{C}$ and $\mathrm{N}$ concentration segregated at grain boundary calculated with Hillert-Ohtani model. The effect of $\mathrm{N}$ is considered (a) or neglected (b) in the calculation. (Online version in color.) reported Hall-Petch coefficients $\left(k_{y}\right)$ were plotted as a function of the calculated $\mathrm{C}$ and $\mathrm{N}$ concentrations (Fig. 4(a)). The segregated $\mathrm{C}$ and $\mathrm{N}$ has a linear relationship with $k_{y}$. The C60 (56 ppm C, $11 \mathrm{ppm} \mathrm{N}$ ) exhibited the maximum amount of segregation of 12 at $\% \mathrm{C}+\mathrm{N}$, which resulted in an enlargement of $k_{y}$ to approximately $500 \mathrm{MPa} \cdot \mu \mathrm{m}^{1 / 2}$. In comparison, IF steel with no segregation had a very low $k_{y}$ of approximately $100 \mathrm{MPa} \cdot \mu \mathrm{m}^{1 / 2}$. As a result, it can be concluded that by using thermodynamic calculations with the Hillert-Ohtani model, the $k_{y}$ of ferritic steels can be roughly predicted from their chemical composition and the heat treatment temperature.

Considering the much stronger segregation tendency of $\mathrm{C}$, the effect of $\mathrm{N}$ on the $\mathrm{Fe}-\mathrm{C}-\mathrm{N}$ ternary alloys should be very small. To prove this hypothesis, the $k_{y}$ values were again plotted as a function of $\mathrm{C}$, ignoring $\mathrm{N}$, as shown in Fig. 4(b). Comparison of Figs. 4(a) and 4(b) reveals that the effect of $\mathrm{N}$ on $k_{y}$ is negligibly small. Therefore, it can be inferred that the enlarged $k_{y}$ mainly resulted from the segregated $\mathrm{C}$ in the $\mathrm{Fe}-\mathrm{C}-\mathrm{N}$ alloy because of the much stronger tendency of $\mathrm{C}$ to segregate at the GB compared to N. However, this does not mean that the segregated $\mathrm{N}$ atoms had no effect on $k y$. As previously demonstrated, the enhanced N segregation by low-temperature aging at $373 \mathrm{~K}$ indicates that the $k_{y}$ of ferritic steel increases with increasing segregated $\mathrm{N}$ concentration. ${ }^{7}$

In addition to the above discussion, the effect of substitutional elements, such as $\mathrm{Mn}$ and $\mathrm{Si}$, on the amounts of segregated $\mathrm{C}$ and $\mathrm{N}$ should be also considered because these elements interact with the interstitials and alter the equilibrium concentrations of them at GB. Therefore, the macroscopic mechanical properties of steels might be influenced by $\mathrm{Mn}$ and Si through not only simple solid solution strengthening but also the changing the Hall-Petch coefficient. This is the next key step towards deeply understanding the mechanism of grain refinement strengthening.

\section{Conclusions}

(1) Thermodynamic calculations using the HillertOhtani model can provide a reasonable prediction of the equilibrium $\mathrm{C}$ and $\mathrm{N}$ concentrations segregated at the GB. The McLean model can yield similar results when the fraction of available sites in the GB layer is assumed to be saturated at 0.1 .

(2) The Hall-Petch coefficient $\left(k_{y}\right)$ of ferritic steels increased linearly with increasing concentrations of segregated $\mathrm{C}$ and $\mathrm{N}$. Therefore, using the above thermodynamic calculations, we can predict the $k_{y}$ of $\mathrm{Fe}-\mathrm{C}-\mathrm{N}$ system in ferritic steels based on the chemical composition and heat treatment temperature. However, because $\mathrm{C}$ has a much stronger segregation tendency than $\mathrm{N}$, the segregation can be calculated by considering only the $\mathrm{C}$ content.

\section{REFERENCES}

1) E. O. Hall: Proc. Phys. Soc. B, 64 (1951), 747.

2) K. Takeda, N. Nakada, T. Tsuchiyama and S. Takaki: ISIJ Int., 48 (2008), 1122.

3) D. McLean: Grain Boundaries in Metals, Clarendon Press, Oxford, UK, (1957), 116.

4) E. D. Hondros and M. P. Seah: Metall. Trans. A, 8 (1977), 1363.

5) M. Hillert: Lectures on the Theory of Phase Transformations, ed. by H. I. Aaronson, Metallurgical Society of AIME, New York, (1975), 36.

6) H. Ohtani and M. Enoki: Proc. 5th ISSS, The Iron and Steel Institute of Japan, Tokyo, (2017), 65

7) S. Araki, K. Fujii, D. Akama, T. Tsuchiyama, S. Takaki, T. Ohmura and J. Takahashi: ISIJ Int., 58 (2018), 1920

8) H. J. Grabke: Steel Res., 57 (1986), 178

9) J. Takahashi, K. Kawakami, K. Ushioda, S. Takaki, N. Nakata and T. Tsuchiyama: Scr. Mater., 66 (2012), 207. 